\title{
Auditors' Perception on the Impact of Artificial Intelligence on Professional Skepticism and Judgment in Oman
}

\author{
Gopalan Puthukulam, Anitha Ravikumar*, Ravi Vinod Kumar Sharma, Krishna Murthy Meesaala \\ Department of Business Studies, University of Technology and Applied Sciences (HCT), Muscat, Sultanate of Oman
}

Received July 26, 2021; Revised September 18, 2021; Accepted October 17, 2021

\section{Cite This Paper in the following Citation Styles}

(a): [1] Gopalan Puthukulam, Anitha Ravikumar, Ravi Vinod Kumar Sharma, Krishna Murthy Meesaala , "Auditors' Perception on the Impact of Artificial Intelligence on Professional Skepticism and Judgment in Oman," Universal Journal of Accounting and Finance, Vol. 9, No. 5, pp. 1184 - 1190, 2021. DOI: 10.13189/ujaf.2021.090527.

(b): Gopalan Puthukulam, Anitha Ravikumar, Ravi Vinod Kumar Sharma, Krishna Murthy Meesaala (2021). Auditors' Perception on the Impact of Artificial Intelligence on Professional Skepticism and Judgment in Oman. Universal Journal of Accounting and Finance, 9(5), 1184 - 1190. DOI: 10.13189/ujaf.2021.090527.

Copyright $@ 2021$ by authors, all rights reserved. Authors agree that this article remains permanently open access under the terms of the Creative Commons Attribution License 4.0 International License

\begin{abstract}
Technology is an inevitable part of businesses and human lives. It has brought about substantial changes in the way businesses and operations are conducted. A business organization has to perform auditing which involves analyzing and testing a large volume of financial transactions. In manual auditing, testing and analyzing the entire transactions in a business are not possible. The usage of artificial intelligence (AI) and Machine Learning (ML) not only allows testing the entire financial transactions in a business but also helps improve audit efficiency. Audit efficiency relates to the professional skepticism and professional judgment demonstrated by the auditors. The core purpose of the research is to understand the perception of auditors on the impact of such technologies on professional skepticism and the judgment of internal auditors in improving audit efficiency. To understand the impact of AI and ML, various factors influencing the use of $\mathrm{AI}$ and ML and the challenges were considered. Data were collected from 169 respondents spanning across all sectors in Oman using a structured questionnaire. The collected data were analyzed using correlation to determine the relationship between AI and ML-assisted auditing practices and professional skepticism and professional judgment. Results indicate that AI and ML-assisted auditing practices have a strong positive relationship with professional skepticism and professional judgment. This proves that AI and ML have an impact on professional skepticism and professional
\end{abstract}

judgment. Moreover, it helps in improving the detection of errors and material misstatements. Even though the advantages of AI and ML outweigh manual auditing, the complete replacement of human beings with AI and ML should be considered with caution. Hence, auditing must be carried out with the help of AI and ML along with human intervention in improving auditing efficiency.

Keywords Artificial Intelligence, Machine Learning, Perception, Professional Judgment, Scepticism, Performance, Audit Quality, Audit

\section{Introduction}

Professional skepticism refers to "an attitude that includes a questioning mind and a critical assessment of audit evidence". This means that auditors who demonstrate a high level of professional skepticism are auditors who need evidence that is more convincing relatively in terms of quality and quantity. Professional skepticism is considered as an essential part of audit quality [18].

Professional judgment is described as the key to a successful audit engagement. Correct usage of professional judgment means they must understand the rules and standards related to accounting and audit. ISA 200 emphasizes the importance of exercising professional 
judgment in the planning stage and the audit work. Judgment by an auditor is based on training, experience and knowledge, which helps the auditors develop the skills needed to achieve reasonable judgments [8].

We can find plenty of evidence to show that the auditors do not make trustworthy judgments. The judgments, which do not have quality, will have serious effects on the users of the judgment results [5].

To make a better and informed decision, Information and Communication Technology provides much - needed data, which is otherwise not possible. Hence, the auditing profession can deliver the output with more efficiency at a lower cost. Increasing investment of auditing companies in Information Technology has positively affected the performance of auditing as well. Information Technology has reduced risk, made auditing job easier, simpler and more over it helps to handle huge volumes of data thereby saving time [1].

Information Technology allows an auditor to work and analyze a large volume of financial data /transactions instead of testing only a sample, the auditor can test $100 \%$ of a company's transactions [12]. Thus, the development of new technologies like AI and ML gives an auditor deeper insight into the operations of the company thereby understanding and assessing risk potential in each audit area [4]. The auditor must be familiar with this new advanced and updated technology and up to date with it so that they can increase audit efficiency.

Artificial Intelligence can bring huge benefits to auditing like cost-reduction, the ability to handle and process an enormous volume of data efficiently that ultimately results in increasing the efficiency of auditing [4]. Before the introduction of Artificial Intelligence, auditors had to manually test the data randomly to know the factors that should be reviewed. It was less effective when compared with Artificial Intelligence. It signals the auditor if certain transactions need more scrutiny. It also helps the auditor to classify the trends and patterns from the data sets, which is much faster than doing it manually [2].

The key subset of Artificial Intelligence is Machine Learning, which enables the system to learn and improve from the experience automatically without any need for human interference [9]. In Machine learning, computers act like human brains. This technology is bound to transform every industry and profession and Auditing will no longer be an exception [14].

Machine Learning not only provides remarkable audit quality and audit speed but also minimizes the risk [9]. The Auditors will be able to analyse all the data instead of checking the samples. Though many studies examined the importance and extent of the use of Information Technology in Auditing practices, there is a lack of evidence in the literature review, which has studied the impact of Artificial Intelligence and Machine Learning on professional Skepticism and professional judgment. Thus, to comprehend the application of Artificial Intelligence and
Machine Learning, how it helps in enhancing professional skepticism and professional judgment a study was undertaken. In addition, how AI and ML assisted professional skepticism and judgment can improve the overall audit efficiency of internal audit, the various factors which affect the use of AI and ML as well as to study the challenges in applying AI and ML in professional skepticism and professional judgment of internal auditors.

\section{Review of Related Literature}

To gain more knowledge on the topic and find out the research gap a thorough examination on the published information has been made by the authors and the literature reviews are presented below:

Artificial Intelligence is a combination of hardware and software that works like the human brain which can evaluate, decide and carry out complex judgment processes based on the available data [24]. AI-powered computer software systems can improve performance and make life easy for the human beings by taking up routine transactions [19].

Technology is no longer a luxury but a necessity in today's business world. Every profession must be equipped to adapt to the changes in technology to enjoy the fruit of it and auditing is not an exception. Financial auditing is going to use these kinds of advanced technologies like Artificial Intelligence and Machine learning, Robotics, and the like in the near future [11].

Technology is advancing at a very high speed and that brought a change in the manner conventional accounting and book keeping works. This adds pressure as well as opportunities to auditing firms to adopt the new age practices in the process of auditing and reporting. This promotes the introduction of AI based automated auditing, data analytics, risk assessment, and enhanced skepticism and judgment [15].

Advancement in technology, data analytics, AI in auditing would be more important in the coming years. AI requires the use of big data and powerful processing. The impact of AI on auditing is particularly evident in the field of data acquisition, verification of transaction processing, and reporting [14].

Using big data, firms can create process and analyze complicated and incoherent data into meaningful information. AI and ML propel for easy, accurate, and comprehensive auditing that enhances the accountability and credibility of financial reports ensures the quality of the audit, and helps the stakeholders to make reliable decisions [17].

AI can identify and process information that is relevant for the auditor's analysis and decision-making. It can also extract valuable information from digital documents that improve the decision-making capacity of the auditors [14]. AI is beneficial and smart which saves time and effort of 
the auditors, increases the level of accuracy, improves the speed of data analysis. Currently, auditors are using AI and ML in the field of testing of transactions, preparation of audit work in papers, analysis, and risk assessment [23].

Robot Process Automation helps auditors to automate rule-based tasks that are repetitive and manual. This may shift the auditors' role to the next level by focusing on higher-order thinking skills, leading to better audit quality and overall audit efficiency [16].

AI can reduce the time and effort for transaction analysis. This may also reduce the cost of auditing. However, this cannot envisage for decision-making. Decision-making depends upon professional judgment and professional skepticism of auditors. Hence, AI and ML are unlikely to replace professional skepticism and judgment because it requires great extent of human element [3].

The application of $\mathrm{AI}$ and $\mathrm{ML}$ in auditing is still in its early stage. However, auditors can use AI and ML to enhance the effectiveness of audit procedures in economical ways [13]. According to AICPA Canada, the technology is ever changing, and embracing automation, AI and ML in auditing enhances overall audit efficiency. Auditors cannot be replaced by automation but there will be a paradigm shift in the auditor's role and how they perform audits after using AI and ML in auditing [7].

AI and ML help auditors to focus more on critical areas like estimation; assessment of risk potentials identifies anomalies rather than focusing on routine and repetitive transactions [16].

Audit firms are concentrating more on the application of $\mathrm{AI}$ and $\mathrm{ML}$ in auditing that helps them in avoiding challenging tasks such as evaluating complex estimates [6]. Professional skepticism is difficult to measure and AI and ML cannot replace it. It can only increase overall audit efficiency [18].

Comparison of manual auditing tools with that of AI assisted auditing techniques shows that the use of artificial intelligence in auditing (fuzzy front-end (FFE)) led to 92\% improvement in audit efficiency and 95\% effectiveness comparing with human auditors [25].

An examination of AI and its perceived ease, usefulness, and contribution to audit quality in Jordanian audit firms revealed that $\mathrm{AI}$ assisted system and augmented AI system is easy to use in auditing whereas an autonomous auditing system is perceived to be difficult to use. The auditors think that assisted AI system is of great help in auditing to contribute to the improvement of audit quality when compared with the augmented AI systems. An autonomous auditing system is found to be of less use when compared with other AI systems [26].

Usage of auto coders ( a technique based on AI) as an unsupervised method evaluated in auditing in a practical case study showed that auto coders can support the auditors in the audit execution and audit planning processes to improve the quality of internal audit engagement [27].

Investigation of how the audit quality can be improved during the period of pandemic strongly recommend auditing firms to invest more in digital technologies such as artificial intelligence, block chain and data function because this is expected to enhance the effectiveness and flexibility of communication between auditor and clients [28].

The capabilities of AI are maligned with the Gartner's 2018 CIO Agenda Survey indicating that 85 percent of AI projects are going to convey misleading results due to bias in data, computations, or step up teams. Another risk associated with AI is that the AI will not delete the irrelevant data and will have a dilution impact. Nevertheless AI will eventually learn and create patterns based on irrelevant data and thus will possess lack of prediction and concrete confirmation [29]. Further, such inclusion of irrelevant data can influence the audit process and audit quality [30]

Professional skepticism and judgment will remain a crucial area for every audit irrespective of the use of any technology [20]. The introduction of AI and ML is in an early stage in the audit profession should be considered by the internal auditors to enhance, complement and facilitate audit procedures [13].

\section{Data and Methodology}

Primary data was collected by preparing a structured questionnaire consisting of two parts, which included demographic profile such as respondent's age, experience, Educational qualification, Gender, and Industry. The second part consisted of 21 statements of five-point Likert scale questions related to auditing, ML and AI ranging from strongly agree and strongly disagree. The questionnaire also included three open-ended questions on the auditors' opinion on the use of AI and ML in auditing. With the help of friends, colleagues and relatives, a questionnaire link was sent to 200 internal auditors through mails to collect the data required for the study. Only 169 out of 200 internal auditors responded. All the questionnaires were usable. Collection of secondary data has been carried out through websites, journals etc. The authors used correlation to analyze the primary data with the help of SPSS 16.0.

\section{Data Analysis and Findings}

\subsection{Demographic Profile}

Table 1 shows the demographic profile of respondents. Out of 169 internal auditors responded to the questionnaire, 112 of whom were male and 57 were female. 49 respondents have less than 4 years of experience and 50 respondents have more than 4 years but less than 8 years of experience. 28 respondents have more than 8 years but less 
than 13 years of experience, 24 respondents have more than 13 years but less than 18 years and only 18 respondents have more than 18 years of experience as internal auditors. Regarding the qualification of auditors, 111 of the respondents have a professional degree in auditing and the rest of them have bachelors, masters and 8 of them have only diploma. Respondents from the insurance and retail sectors were found to be very few while other sectors like banking, manufacturing and Government sector auditors responded more or less equally.

Table 1. Demographic profile of respondents

\begin{tabular}{|c|c|c|c|}
\hline \multicolumn{2}{|c|}{ Demographic profile } & \multirow{2}{*}{$\begin{array}{c}\text { Number } \\
112\end{array}$} & \multirow{2}{*}{$\begin{array}{c}\begin{array}{c}\text { \% of } \\
\text { respondents }\end{array} \\
66\end{array}$} \\
\hline Condor & Male & & \\
\hline Gentuet & Female & 57 & 34 \\
\hline \multirow{5}{*}{$\begin{array}{c}\text { Experience (in } \\
\text { years) }\end{array}$} & $\begin{array}{c}\text { Less than } 4 \text { years } \\
\text { of experience }\end{array}$ & 49 & 29 \\
\hline & $\begin{array}{c}4 \text { to less than } 8 \\
\text { years }\end{array}$ & 50 & 30 \\
\hline & $\begin{array}{c}8 \text { to less than } 13 \\
\text { years }\end{array}$ & 28 & 16.5 \\
\hline & $\begin{array}{c}13 \text { to less than } 18 \\
\text { years }\end{array}$ & 24 & 14 \\
\hline & $\begin{array}{c}\text { More than } 18 \\
\text { years }\end{array}$ & 18 & 10.5 \\
\hline \multirow{4}{*}{ Qualification } & $\begin{array}{c}\text { Professional } \\
\text { degree }\end{array}$ & 111 & 65.5 \\
\hline & Bachelors & 30 & 18 \\
\hline & Masters & 20 & 12 \\
\hline & Diploma & 8 & 4.5 \\
\hline \multirow{4}{*}{$\begin{array}{c}\text { Business } \\
\text { sector }\end{array}$} & $\begin{array}{c}\text { Insurance and } \\
\text { Retail } \\
\end{array}$ & 6 & 3.5 \\
\hline & Banking & 74 & 43.5 \\
\hline & Manufacturing & 35 & 21 \\
\hline & $\begin{array}{c}\text { Government } \\
\text { sector }\end{array}$ & 54 & 32 \\
\hline
\end{tabular}

Source: Primary data

\subsection{Validity of Questionnaire}

Content validity: The content validity was verified by using review of literature, Auditors' feedback and conducting a pilot study with nearly 10 internal auditors who are experts in the field.

Reliability: Table 2 shows the reliability statistics.

To test the reliability, Cronbach's Alpha was used. According to Taber, K.S [21], Cronbach's alpha is the most used to check scale reliability or internal consistency. George Ursachi et al. [22] indicate that $0.6-0.7$ is an acceptable level of reliability, and 0.8 or greater is a very good level. In our study, Cronbach's alpha is 0.924 , which means its reliability level is very good.

Table 2. Reliability statistics

\begin{tabular}{|c|c|}
\hline Cronbach's Alpha & Number of items \\
\hline 0.924 & 21 \\
\hline
\end{tabular}

Source: Authors Calculation
Table 3. Perception of Internal Auditors on the impact of Artificial Intelligence and Machine Learning on Auditors' professional Skepticism and Judgment (in percentages)

\begin{tabular}{|l|l|l|l|l|l|}
\hline $\begin{array}{l}\text { Internal Auditors' } \\
\text { Perception S.A* }\end{array}$ & A* & $\mathrm{N}^{*}$ & $\mathrm{D}^{*}$ & S.D* \\
\hline $\begin{array}{l}\text { Application of AI and } \\
\text { ML assisting in } \\
\text { enhanced quality and } \\
\text { reliability of auditing }\end{array}$ & 27.2 & 53.8 & 17.2 & 0.6 & 1.2 \\
\hline $\begin{array}{l}\text { AI and ML assisted } \\
\text { Professional Scepticism } \\
\text { and Professional } \\
\text { Judgment in improving } \\
\text { overall audit efficiency } \\
\text { of internal audit }\end{array}$ & 22.5 & 60.9 & 3.6 & 13 & 0 \\
\hline $\begin{array}{l}\text { AI and ML assisted } \\
\text { Professional Scepticism } \\
\text { and Professional } \\
\text { Judgment helps in the } \\
\text { detection of error and } \\
\text { misstatements }\end{array}$ & 29 & 41.4 & 26 & 3 & 0.6 \\
\hline $\begin{array}{l}\text { Challenges faced in the } \\
\text { implementation of AI } \\
\text { and ML in auditing and } \\
\text { the application of AI } \\
\text { and ML in auditing }\end{array}$ & 21.9 & 53.8 & 21.9 & 2.4 & 0.6 \\
\hline
\end{tabular}

Source: Primary data

*(Note: SA-Strongly Agree, A-Agree, N-Neutral, D-Disagree, SD-Strongly Disagree)

Table 3 shows the perception of internal auditors on the impact of Artificial Intelligence and Machine Learning on Auditors' professional Skepticism and Judgment. More than $50 \%$ agreed that the application of $\mathrm{AI}$ and $\mathrm{ML}$ enhances the quality and reliability of auditing. More than $60 \%$ agreed that AI and ML assisted professional Scepticism and professional Judgment helps in improving the overall audit efficiency of internal audits. $41.4 \%$ agreed that AI and ML assisted professional Scepticism and professional Judgment helps in the detection of errors and misstatements. 53.8\% agreed that there are challenges in the implementation and application of AI and ML in auditing.

Table 4. Correlation between application of AI and ML assisting in enhanced quality and reliability of auditing

\begin{tabular}{|l|c|}
\hline Application of AI and ML in auditing & $\begin{array}{c}\text { Enhanced } \\
\text { professional } \\
\text { Scepticism and } \\
\text { professional } \\
\text { Judgment }\end{array}$ \\
\hline $\begin{array}{l}\text { AI in auditing helps in converting } \\
\text { unstructured data to reliable and } \\
\text { qualitative information }\end{array}$ & 0.752 \\
\hline $\begin{array}{l}\text { AI helps assessment of audit evidence as } \\
\text { part of natural language processing }\end{array}$ & 0.683 \\
\hline $\begin{array}{l}\text { AI and ML processes large data in a } \\
\text { shorter period that enhances quality of risk } \\
\text { assessment }\end{array}$ & 0.561 \\
\hline $\begin{array}{l}\text { AI and ML enhances the credibility of } \\
\text { financial statements }\end{array}$ & 0.726 \\
\hline $\begin{array}{l}\text { AI and ML ensure accuracy of financial } \\
\text { data }\end{array}$ & 0.655 \\
\hline
\end{tabular}

Source: Authors’ Calculation 
Table 4 shows the correlation between Application of AI and ML in auditing and enhanced professional Skepticism and professional Judgment. The results show that AI and ML in auditing helps in converting unstructured data to reliable and qualitative information as well as enhancing the credibility of financial statements. Manual conversion of unstructured data into structured data is time consuming and it will less credible. Only credible and structured data will help the auditors in enhancing professional skepticism and judgment. This clearly reveals the importance of AI and ML in auditing.

The result shows that there is a high positive correlation between the application of AI and ML in auditing and the enhancement of professional skepticism and judgment of internal auditors in selected firms in Oman. AI and ML help in converting large volumes of unstructured data into useful, reliable and qualitative information that helps auditors in applying professional skepticism and judgment. This is contrary to conventional auditing practices of verifying, only concluding with sample quantitative data and reaching a conclusion.

The application of AI and ML increases the overall audit efficiency. The results also show that the application of AI and ML in auditing help in assessing a large volume of audit evidence within a short period through various techniques like natural language processing. This enables the auditor to have a better understanding of various areas of auditing and reaching a more precise conclusion. The result shows that there is a close correlation between the application of AI and ML in enhancing the credibility of financial statements. The credibility of a financial statement highly depends on how an auditor applies his professional judgment and skepticism while auditing [10]. This is possible through the assessment of large-scale data/evidence to reach a meaningful conclusion with less cost through the application of AI and ML in auditing. Lastly, the result also shows that the AI and ML ensure accuracy of financial data that enable the auditor to have an enhanced professional skepticism and judgment. Since the data and information are collected and processed by the auditors with the help of applications backed by AI and ML, the chances of errors are very less.

Table 5 displays the correlation between AI and ML assisted professional Scepticism and professional Judgment in improving the overall audit efficiency of internal audits. The correlation results reveal a clear relationship between usage of $\mathrm{AI}$ and $\mathrm{ML}$ in auditing practices in improving the overall audit efficiency of internal audit with a correlation co-efficient of more than 0.6 .

Table 6 shows the Correlation between $\mathrm{AI}$ and ML assisted professional Scepticism and professional Judgment helps in the detection of errors and misstatements. Usage of AI and ML in auditing is more useful for detecting errors and misstatements. Only random verification is done to ensure the detection of errors and misstatements in manual auditing. However, AI and ML enable us to verify the whole data set or accounts. This helps in determining errors and frauds without much effort.

Table 5. Correlation between AI and ML assisted professional Scepticism and professional Judgment in improving overall audit efficiency of internal audit

\begin{tabular}{|l|c|}
\hline $\begin{array}{l}\text { AI and ML assisted professional } \\
\text { Scepticism and professional Judgment }\end{array}$ & $\begin{array}{c}\text { Overall audit } \\
\text { efficiency of } \\
\text { internal audit }\end{array}$ \\
\hline $\begin{array}{l}\text { AI and ML works like the human brain in } \\
\text { data validation and process control }\end{array}$ & 0.343 \\
\hline $\begin{array}{l}\text { AI and ML assist in testing the effectiveness } \\
\text { of internal controls in a better manner }\end{array}$ & 0.721 \\
\hline $\begin{array}{l}\text { AI and ML can enhance better judgment on } \\
\text { management estimates }\end{array}$ & 0.749 \\
\hline $\begin{array}{l}\text { AI and ML assists the auditor in testing the } \\
\text { judgment of various account balances and } \\
\text { estimates }\end{array}$ & 0.769 \\
\hline $\begin{array}{l}\text { AI and ML is effective in cost control and } \\
\text { time management }\end{array}$ & 0.645 \\
\hline $\begin{array}{l}\text { AI and ML enhances the level of assurance } \\
\text { compared to manual auditing }\end{array}$ & 0.704 \\
\hline
\end{tabular}

Source: Authors Calculation

Table 6. Correlation between AI and ML assisted professional Scepticism and professional Judgment helps in the detection of errors and misstatements

\begin{tabular}{|l|c|}
\hline $\begin{array}{l}\text { AI and ML assisted professional } \\
\text { Scepticism and professional Judgment }\end{array}$ & $\begin{array}{c}\text { Detection of errors } \\
\text { and misstatements }\end{array}$ \\
\hline $\begin{array}{l}\text { AI helps in detecting errors and frauds with } \\
\text { predictive analysis }\end{array}$ & 0.748 \\
\hline $\begin{array}{l}\text { AI and ML helps in the critical evaluation of } \\
\text { audit evidence for enhancing audit quality }\end{array}$ & 0.793 \\
\hline $\begin{array}{l}\text { AI and ML helps to find material } \\
\text { misstatements easily }\end{array}$ & 0.773 \\
\hline
\end{tabular}

Source: Authors Calculation

Table 7. Correlation between challenges faced in the implementation of $\mathrm{AI}$ and $\mathrm{ML}$ in auditing and the application of $\mathrm{AI}$ and $\mathrm{ML}$ in auditing

\begin{tabular}{|l|c|}
\hline Challenges faced in the implementation & $\begin{array}{c}\text { Application of AI } \\
\text { and ML in auditing }\end{array}$ \\
\hline $\begin{array}{l}\text { High cost affects the implementation of } \\
\text { AI and ML in auditing }\end{array}$ & 0.678 \\
\hline $\begin{array}{l}\text { The overall digitalization of the firm } \\
\text { affects the implementation of AI and ML } \\
\text { in auditing }\end{array}$ & 0.550 \\
\hline $\begin{array}{l}\text { Support of top management affects the } \\
\text { implementation of AI and ML }\end{array}$ & 0.649 \\
\hline $\begin{array}{l}\text { Data validation is going to be a major } \\
\text { challenge in the implementation of AI and } \\
\text { ML in auditing }\end{array}$ & 0.668 \\
\hline $\begin{array}{l}\text { Requirement of training of auditors and } \\
\text { employees }\end{array}$ & 0.766 \\
\hline $\begin{array}{l}\text { Ethical consideration of data may be a } \\
\text { challenge in the implementation of AI and } \\
\text { ML }\end{array}$ & 0.724 \\
\hline $\begin{array}{l}\text { Updating or implementation of AI and } \\
\text { ML may reduce the working interest } \\
\text { among the audit team. }\end{array}$ & 0.725 \\
\hline
\end{tabular}

Source: Authors Calculation

Table 7 shows correlation between the challenges faced in the implementation of $\mathrm{AI}$ and $\mathrm{ML}$ in auditing and its application. Transforming from manual auditing to technology-based auditing will take its course as it involves 
high cost, needs support from top management and the training of auditors. A very important challenge posed in using AI and ML in auditing is the consideration of ethics in its implementation. Considering the advantages of implementing AI and ML in auditing, challenges are few and could be overcome with a proper implementation plan.

\section{Discussions}

The results showed the following impacts:

1. Majority of the internal auditors agreed that Artificial intelligence and Machine learning play an important role in enhancing the quality, reliability and overall audit efficiency. It also helps in the detection of errors and misstatements, subsequently helping the auditors on the professional skepticism and better judgment.

2. Highly positive correlation between the application of Artificial intelligence and Machine learning in auditing and enhancing the quality and reliability of auditing is found. This means that Artificial intelligence and Machine learning assisted has improved the quality and reliability of information supplied in the financial statements, through better professional skepticism and judgment.

3. Artificial intelligence and Machine learning assisted professional Scepticism and professional Judgment have a positive correlation with the detection of errors and misstatements, because $\mathrm{AI}$ and $\mathrm{ML}$ ensure the verification of complete data as opposed to manual auditing. When compared with manual auditing, AI and ML assisted auditing is highly reliable in the detection of errors and frauds, unlike random verification of data when manually done.

4. A positive correlation is revealed between challenges in implementation and application of Artificial intelligence and Machine learning; hence, the organizations cannot secure the benefits of AI and ML assisted Auditing.

\section{Conclusions}

The researchers have undertaken this study to shed light on the impact of AI and ML-assisted auditing practices followed by companies in improving the professional skepticism and judgment of auditors. The results indicate that $\mathrm{AI}$ and $\mathrm{ML}$ assisted auditing play a major role in improving the quality and reliability of information in financial statements and it helps to check the complete data of an organization. This means that detection of errors and frauds in AI and ML assisted auditing is easy and convenient. Apart from the detection of errors and frauds, AI and ML assisted auditing fairly improve the overall efficiency of auditing. Despite being advantageous in many aspects, organizations have to face several challenges in the application of $\mathrm{AI}$ and $\mathrm{ML}$ in internal auditing. A fully digitalized auditing will not consider data from ethical viewpoint and validation of data is not considered. To validate the data from an ethical viewpoint internal auditors' intervention is necessary. Hence, it is obvious that auditors 'role is irreplaceable but there will be a change in the auditor's role and the methodology involved in the auditing process [7].

Other major challenges in implementing $\mathrm{AI}$ and $\mathrm{ML}$ in auditing are the high cost of implementation and the requirement of training internal auditors in terms of AI and $\mathrm{ML}$ in auditing. As $\mathrm{AI}$ and $\mathrm{ML}$ have to be updated continuously according to the latest advancements, along with auditors' training that means additional expenses for the company. This will pose a major challenge to the organizations, which are already struggling with limited finances.

As rightly pointed out, technology is no longer a luxury but a necessity in today's business world. Technology and innovation have been a catalyst for the advancement and change of the business world that we have today. Every profession must be equipped to adapt to the changes in technology and auditing is not an exception [11]. Thus, considering the contemporary challenges faced in auditing as never before, the implementation of $\mathrm{AI}$ and $\mathrm{ML}$ has to be carried out with a robust implementation plan.

\section{REFERENCES}

[1] ACCA, Technology is transforming the accountancy profession, and has the potential to revolutionize audit, Professional insight report, Audit and Technology, 2019, https://www.accaglobal.com> professional-insights.

[2] Andrew Struthers, Kyle Nesgood, Artificial Intelligence and Internal Audit: A Pragmatic Perspective. Protiviti, 2020.

[3] Alderman, J., Auditing in the Smart Machine Age. Graziadio Business Review, 22(1), 2019, https://gbr.pepperdine.edu/2 019/03/auditing-in-the-smart-machine-age/.

[4] Bizarro, P.A. and Dorian, M., Artificial Intelligence: The Future of Auditing, Internal Auditing, vol.32, no. 5, 21-26, 2017.

[5] Bonner, S. E., Judgment and decision making in accounting, Upper Saddle River, NJ: Pearson, Prentice Hall, 1st Edition, 2008.

[6] Commerford, B. P., Dennis, S. A. and Joe, J. R. and Ulla, J., Man Versus Machine: Complex Estimates and Auditor Reliance on Artificial Intelligence, 2021, Available at SSRN: https://ssrn.com/abstract=3422591.

[7] AICPA, The Data-Driven Audit: How Automation and AI are changing the Audit and the Role of the Auditor, Canada, CPA, 2020.

[8] Chis, A.O. \& Achim, A.M., Professional Judgement. The Key to a Successful Audit, SEA - Practical Application of Science, Romanian Foundation for Business Intelligence, 
Editorial Department, issue 5, 217-222, 2014.

[9] Dickey,G. Blanke,S. Seaton,L, Machine Learning in Auditing: Current and Future Applications, The CPA Journal, vol. 89, no. 6, 16-21, 2019.

[10] Ghanoum, S., Integration of Artificial Intelligence in Auditing: The Effect on Auditing Process, 2020, https://www.diva-portal.org/smash/get/diva2:1446778/FUL LTEXT01.pdf

[11] Giles, K. M., How Artificial Intelligence and Machine Learning will Change the Future of Financial Auditing. An Analysis of the University of Tennessee's Accounting Graduate Curriculum https://trace.tennessee.edu/utk_chanho noproj/2259, 2019.

[12] Harris, S., The future of auditing: Technology brings opportunities and challenges, vol. 37, no. 2, 151-164, 2019.

[13] Jooman, S., The influence of artificial intelligence on the future of the internal auditing profession in South Africa, 2019.

[14] Kokina,J. \& Davenport,T.H, The Emergence of Artificial Intelligence: How Automation is changing Auditing, Journal of Emerging Technologies in Accounting, vol. 14, no.1, 115-122, 2017.

[15] Keskinen, M. T., Automation and the transformation of the audit process: A qualitative research on the impact of automation on the audit process, Digitala Vetenskapliga Arkivet, 2019, Available at: http://urn.kb.se/resolve?urn=ur n:nbn:se:umu:diva-160152.

[16] Mofitt,C.K., Rozario,A.M. \& Vasarhelyi, M. A., Robotic Process Automation for Auditing, Journal of Emerging Technologies in Accounting, vol. 15, no. 1, 1-10, 2018.

[17]Hu, K.-H., Chen, F.-H., Hsu, M.-F., \& Tzeng, G.-H., Identifying key factors for adopting artificial intelligence-enabled auditing techniques by joint utilization of fuzzy-rough set theory and MRDM technique. Technological and Economic Development of Economy, vol. 27, no. 2, 459-492, 2021.https://doi.org/10.3846/tede.2020.1 3181

[18] Nelson, M.W., A Model and Literature Review of Professional Skepticism in Auditing, Auditing: A Journal of Practice \& Theory, vol. 28, no. 2, 1-34, 2009, https://doi.org/10.2308/aud.2009.28.2.1

[19] Coyne,M.M， Hooper,M.J. \& Sicchitano,K.J, Artificial intelligence: The future of Internal Auditing, Tone at the Top, The Institute of Internal Auditors Inc., Issue no. 85, 2017.
[20] Sweet, P., Artificial intelligence cannot replace professional judgment for auditors, https://www.accountancydaily.co/arti ficial-intelligence-cannot-replace-professional-judgment-au ditors, 2019.

[21] Taber, K.S., The Use of Cronbach's Alpha When Developing and Reporting Research Instruments in Science Education. Research in Science Education, vol. 48, 1273-1296, 2018. https://doi.org/10.1007/s11165-016-9602-2

[22] Ursachi, G., Horodnic,I.A. \& Zait,A., How reliable are measurement scales? External factors with indirect influence on reliability estimators, 7th International Conference on Globalization and Higher Education in Economics and Business Administration, GEBA 2013, Procedia Economics and Finance vol. 20, 679 - 686, 2015.

[23] Yoon,S., A Study on the Transformation of Accounting Based on New Technologies: Evidence from Korea, Sustainability, vol. 12, no. 20, 1-22, 2020, doi:10.3390/su12208669.

[24] Martin, J. R., Robotic Process Automation for Auditing, Journal of Emerging Technologies in Accounting, vol. 1, no. 1, 1-10, 2018.

[25] Khan, R., Adi, E. \& Hussain, O., AI-based audit of fuzzy front end innovation using ISO56002, Managerial Auditing Journal, 2021,http://dx.doi.org/10.1108/MAJ-03-2020-2588

[26] Albawwat, I. \& Frijat, Y. A., An analysis of auditors' perceptions towards artificial intelligence and its contribution to audit quality, Accounting, Vol. 7, no. 4, 2021, Doi:10.5267/j.ac.2021.2.009.

[27] Nonnenmacher,J., Kruse, F., Schumann, G. \& Gomez, J.M., Using auto encoders for data-driven analysis in internal auditing, Proceedings of the Annual Hawaii International Conference on System Sciences. January 5, 2021. Doi:10.24251/hicss.2021.697.

[28] Albitar, K., Gerged, A.M., Kikhia, H. \& Hussainey, K., Auditing in times of social distancing: the effect of COVID-19 on auditing quality. International Journal of Accounting Information Management, Vol. 29, no, 1, 2021, Doi: 10.1108/IJAIM-08-2020-0128.

[29] Schmidt, P. J., Church, K. S., \& Riley, J.. Clinging to excel as a security blanket: investigating accountants' resistance to emerging data analytics technology. Journal of Emerging Technologies in Accounting, 17(1), 33-39, 2020.

[30] Abdelraheem, A., Hussaien, A., Mohammed, M., \& Elbokhari, Y. The effect of information technology on the quality of accounting information. Accounting, 7(1), 191-196, 2020. 